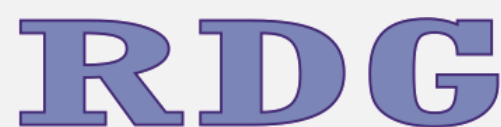

Revista do Departamento de Geografia USP

ISSN 2236-2878
Revista do Departamento de Geografia

Universidade de São Paulo

www.revistas.usp.br/rdg

Volume Especial - XVII SBGFA / I CNGF (2017)

\title{
Caracterização Física dos Microrrelevos de Murundus na Chapada Uberlândia-Uberaba/MG: Discussões Preliminares Sobre Gênese
}

\section{Physical Characterization of Murundus Micro-Relief in Uberlândia-Uberaba/MG Plateau: Preliminary Discussions About Genesis}

\author{
Vinícius Borges Moreira \\ Universidade Estadual de Campinas \\ viniciusmoreira@ige.unicamp.br \\ Archimedes Perez Filho \\ Universidade Estadual de Campinas \\ archi@ige.unicamp.br
}

Resumo: Murundus são microrrelevos típicos do Cerrado brasileiro, comumente encontrados em relevos tabulifores. Este trabalho se propõe a identificar as caracterisiticas físicas de um campo de murundus na nascente do Rio da Rocinha localizada na chapada Uberlândia-Uberaba região do Triângulo Mineiro-MG. Para tal, foram realizados trabalhos de campo para coletar amostras da cobertura superficial com a finalidade de realizar análises gramulométricas. Como técnica auxiliar também foi realizado perfil tranversal com a finalidade de identificar as formas e topografia do campo de murundus. Os principais resultados obtidos foram: identificação de textura muito argilosa para o campo de murundus, ilustrações da forma e cobertura superficial dos murundus e identififcação da variação sazonal do lençol freático, que puderam subisidiar as conclusões sobre aspéctos genéticos em relação as microformas dos murundus.

Palavras chave: Geomorfologia; Covoal; Cerrado; Análise Granulométrica.

\begin{abstract}
Murundus are typical micro-relief of the Brazilian Cerrado, mostly found in plateaus. This work aims to identify the physical characteristics of murundus field at the source of the Rocinha River located in the Uberlândia-Uberaba region of the Triângulo Mineiro-MG. Fieldwork was carried out to collect samples of the surface cover for the purpose of performing gramulometric analysis. A cross sectional profile was also used as an auxiliary technique to identify the forms and topography of the murundus field. The main results were: identification of a very clayey texture for the murundus field illustrations of the shape and surface cover of murundus; identification of the seasonal variation of the water table level. These results can help to answer questions about genetic aspects of murundus microforms.
\end{abstract}

Keywords: Geomorphology; Covoal; Cerrado; Granulometric analysis. 


\section{INTRODUÇÃO}

Comumente encontrados em áreas de relevos tabuliforme na porção central do Brasil recobertos por Cerrados, os microrrelevos de murundus possuem caracteristicas unicas que os diferenciam da paisagem regional. No interior do estado de Minas Gerais, região do Triângulo Mineiro, ocorrem extensas e contínuas chapadas de superfície aplainada que se organizam de forma escalonada, separadas por vales fluviais encaixados. Neste contexto, destaca-se pela ocorrência das microformas analisadas a chapada Uberlândia-Uberaba.

Murundus são microformas ou microrrelevos típicos do Cerrado brasileiro, Figura 1. Caracterizam-se por pequenas elevações ou montículos convexos, possuindo base circular ou elíptica com tamanho variando de 2 a 6 metros de diâmetro na largura e 0,5 à 2 metros de altura (dependendo do local de ocorrência ou estágio de degradação pode variar de tamanho), comumente são associados a termiteiros (PENTEADO-ORELLANA, 1980). De acordo com Schneider (1996) sua vegetação consiste predominantemente em gramíneas e ciperáceas, sendo que sobre os murundus maiores podem ocorrer pequenas espécies arbóreas.

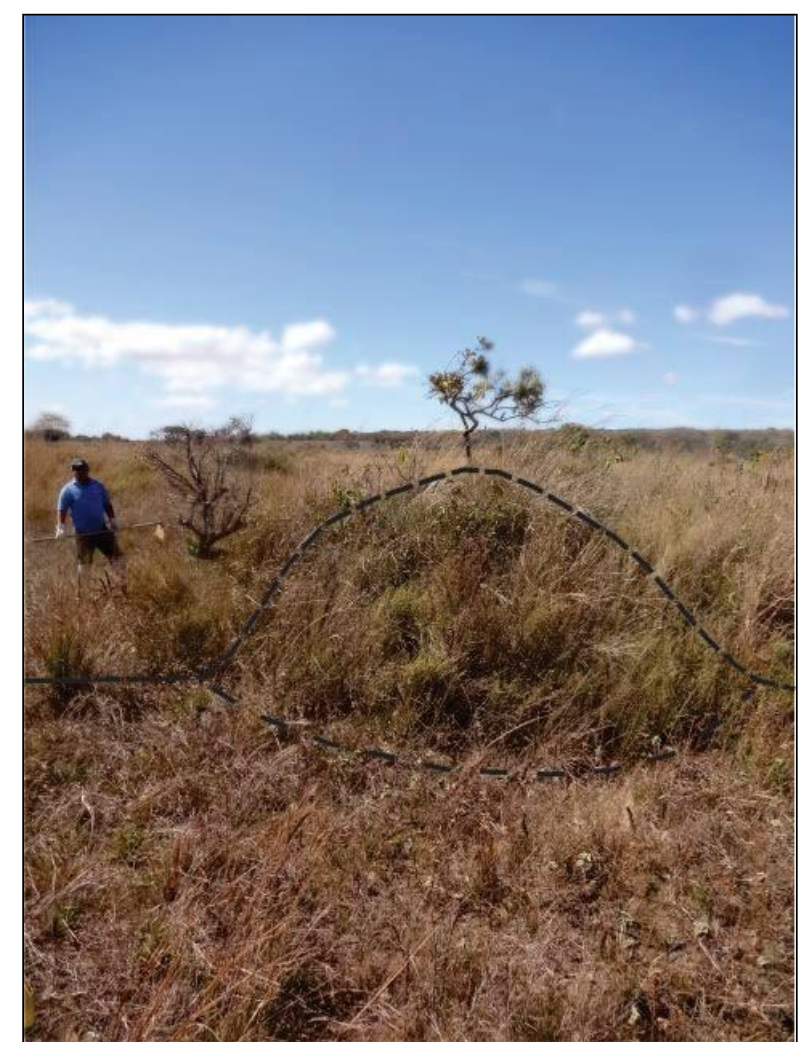

Figura 1 - Microrrelevo de murundu

Por meio de interpretação de imagens aéreas Araújo Neto (1981), denomina a área de ocorrência de microrrelevos como "campos de murundus", estando geralmente associados a rede de drenagem. Constituem-se em áreas deprimidas que possuem formato circular ou de ameba, facialmente detectadas pela ocorrência abundante dos murundus de aspecto "encalombado" que se distribuem caoticamente (SCHNEIDER, 1996).

De acordo com Castro Júnior (2002) os murundus ocorrem em campos aluvionares inundáveis das planícies e depressões, bem como em campos brejosos de encosta de planaltos e serras. Penteado-Orellana (1980) destaca a relação das microformas com a proximidade do lençol freático, apontando que o mesmo ocorre no contado entre a base da encosta e a planície aluvial. Dependendo da região do país onde ocorrem, os murundus são conhecidos por outras denominações, sendo que na região do Triângulo Mineiro possui a designação de "covoal” (SCHNEIDER E SILVA, 1991). 
A partir do exposto objetiva-se identificar as características físicas de um campo de murundus previamente selecionado sobre a chapada Uberlândia-Uberaba, com a finalidade de conhecer sua composição granulométrica. Discussões sobre dinâmica hidrológica e morfologia dos campos de murundus consistem em objetivos secundários, subsidiando algumas conclusões sobre a gênese dos microrrelevos analisados.

Os campos de murundus se localizam em importantes áreas de nascentes dos principais rios que abastecem a cidade de Uberlândia-MG, sendo de relevante importância conhecer a dinâmica destes ambientes para sua preservação e manutenção dos sistemas hidrográficos. Os resultados desta pesquisa também visam colaborar com a divulgação e importância da conservação de ambientes frágeis que consistem os campos de murundus, contribuindo para a elaboração e formulação de políticas públicas aplicadas ao planejamento ambiental.

\section{CARACTERIZAÇÃO DA ÁREA DE ESTUDO}

A chapada Uberlândia-Uberaba é drenada pelas bacias hidrográficas dos rios, Claro, Rocinha e Alto curso do Uberabinha e ribeirões Bom Jardim e Beija-Flor, afluentes do rio Araguari que desaguam no rio Paranaíba. Na encosta voltada para o sul, nascem os rios Tijuco e Uberaba e seus tributários que seguem direção oposta aos rios que drenam a chapada, desaguando no rio Grande. Esta unidade de relevo se configura como importante divisor de águas regional, pois divide rios e córregos que drenam para o rio Paranaíba e Grande. O campo de murundus analisado se localiza na nascente do Rio da Rocinha, Figura 2.

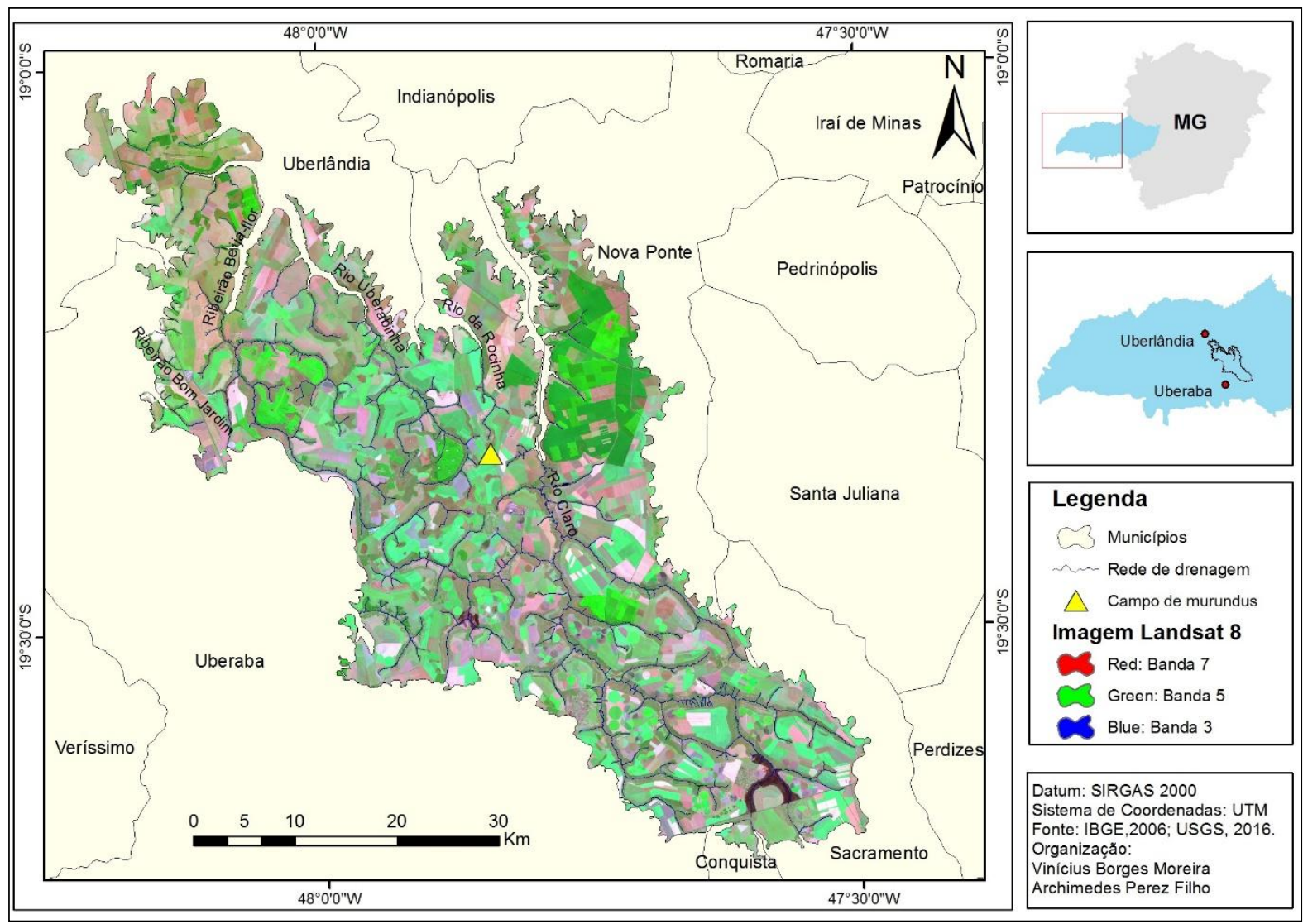

Figura 2 - Localização da Chapada Uberlândia-Uberaba e campo de murundus analisado.

O clima da região é classificado como AW megatérmico, segundo a classificação de Köppen, com chuvas de verão e secas de inverno, de acordo com Rosa et al., (1991). 
A cobertura vegetal da chapada que naturalmente era composta por diversas fitofisionomias do domínio dos Cerrados, porém foi amplamente substituída por culturas anuais mecanizadas e silvicultura, devido às aptidões do relevo, clima e disponibilidade hídrica da região. De acordo com Schneider (1996), esse processo se inicia na década de 1960, sendo a região do Triângulo Mineiro palco da "revolução verde". Programas governamentais como POLOCENTRO (Programa de Desenvolvimento dos Cerrados) incentivaram e financiaram a ampliação das áreas agricultáveis a partir do uso de defensivos agrícolas, fertilizantes e mecanização, diminuindo drasticamente as áreas ocupadas por Cerrado, portanto, afetando também áreas de ocorrência de campos de murundus.

De acordo com mapeamento de solos realizado pela Universidade Federal de Viçosa et al. (2010) escala 1:650.000, ocorrem na chapada predominantemente em interflúvios, rampas e vertentes os Latossolos amarelos e vermelho-amarelos. Restringem-se aos fundos de vale e depressões os Gleissolos que estão intimamente ligados a oscilação de água constante do nível de lençol freático, relação predominante em ambientes de campos de murundus.

Em relação a litologia a chapada é sustentada por derrames basalticos da Formação Serra Geral sob arenitos da Formação Marília, que por sua vez são recobertos por Coberturas Cenozoicas, que constituem a base para a característica de relevo tabular da chapada, proporcionando condições ambientais favoráveis a concentração de umidade (BARCELOS, 1984).

\section{MATERIAIS E MÉTODOS}

Para execussão desta pesquisa foram realizados trabalhos de campo, sendo o primeiro no mês de agosto (período seco) e o segundo no mês de fevereiro (período chuvoso). Desta forma foi possível realizar uma análise comparativa em relação a dinâmica hidrológica do campo de munundus. Foram ecolhidos três pontos para coleta de amostras da cobertura superficial, por meio de tradagem e abertura de trincheiras, para posterior análise granulométrica em laboratório, Tabela 1 e Figura 3. As coletas foram realizaras em duas profundidades $0-20$ cm e 60-80 cm, com excessão do ponto CM06, pois o nível do lençol freático ocorria muito superficiamente o que impediu a coleta na profundidade $60-80 \mathrm{~cm}$, permitindo apenas a coleta somente na profundidade $40-60 \mathrm{~cm}$.

Tabela 1 - Coordenadas geográficas e altimetria dos pontos de coleta

\begin{tabular}{|c|c|c|}
\hline $\begin{array}{c}\text { Código do ponto de } \\
\text { coleta }\end{array}$ & Coordenadas & $\begin{array}{c}\text { Altitude de coleta } \\
\text { (metros) }\end{array}$ \\
\hline CM04 & $\begin{array}{l}19^{\circ} 20^{\prime} 49.80^{\prime \prime} \mathrm{S} \\
47^{\circ} 50 ' 29.40^{\prime \prime} \mathrm{O}\end{array}$ & 975 \\
\hline CM05 & $\begin{array}{l}19^{\circ} 20^{\prime} 48.65^{\prime \prime} \mathrm{S} \\
47^{\circ} 50^{\prime} 27.95^{\prime \prime} \mathrm{O}\end{array}$ & 972 \\
\hline CM06 & $\begin{array}{l}19^{\circ} 20^{\prime} 52.03 " \mathrm{~S} \\
47^{\circ} 50^{\prime} 31.56^{\prime \prime} \mathrm{O}\end{array}$ & 976 \\
\hline
\end{tabular}




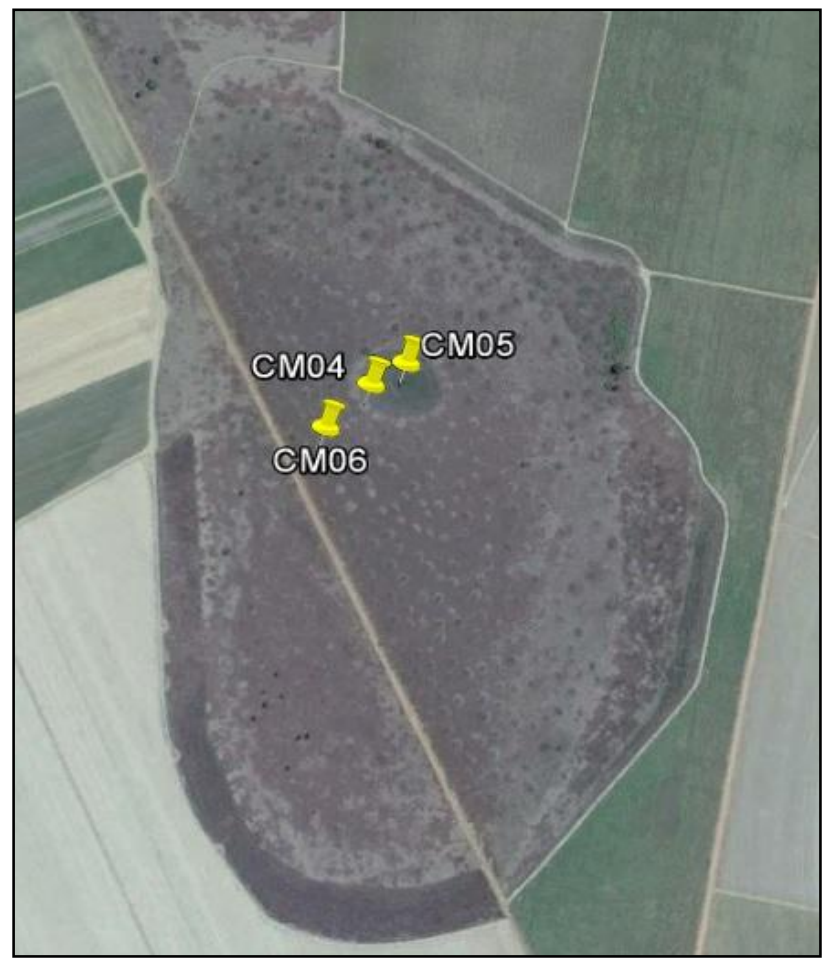

Figura 3 - Localização dos pontos de coleta

Após o procedimento de coleta as amostras foram encaminhadas para o Laboratório de Solos da Faculdade de Engenharia Agrícola na UNICAMP, onde foi realizada a analise granulométrica, com a separação das frações de areia muito grossa, grossa, média, fina e muito fina, além das frações de argila e silte, por meio do método de peneiramento e pipeta, conforme Camargo et al. (1986) e EMBRAPA (1997).

Para realizar caracterização da forma e topografia do campo de murundus e identificação dos locais de coleta foi elaborado um perfil transversal utilizando GPS geodésico TRIMBLE, modelo GEOEXPLORER XH 2008. O aparelho utilizado possui alta precisão, sendo que os dados altimétricos coletados em campo foram pósprocessados em software específico com apoio dos dados da Rede Brasileira de Monitoramento Contínuo dos Sistemas GNSS (RBMC) do IBGE, utilizando estação localizada em Uberlândia-MG para triangulação dos dados. Posteriormente o perfil foi ilustrado com ajuda do software Corel Draw.

\section{DINÂMICA E HIPÓTESES DE ORIGEM DOS MURUNDUS}

Para entendimento dos processos de formação dos campos murundus e da dinâmica hidrológica em sua área de ocorrência, faz-se necessário o levantamento de algumas das principais bibliografias sobre a temática.

A dinâmica hidrológica dos campos de murundus é diferenciada em relação a outros subsistemas de nascentes do Cerrado, por ocorrerem grandes variações sazonais do nível do lençol freático no mesmo ano. De acordo com Schneider e Silva (1991) no período chuvoso, o nível do lençol freático se eleva aproximando-se da superfície, formando uma lagoa temporária no centro da depressão povoada pelos murundus. Durante o período seco o lençol d'agua é rebaixado e o campo de murundus perde praticamente toda água acumulada, secando a lagoa temporária.

De acordo com Castro Junior et al. (2004) que monitoraram o nível d'água de campos de murundus (utilizando piezômetros) durante um ano, pode-se afirmar que a variação do mesmo, ocorre devido a existência de dois níveis de lençóis freáticos distintos, separados por uma camada de argila. O primeiro nível, superficial, varia de acordo com o período de chuvas, sendo o segundo, abastecido pelo primeiro e pelo escoamento subsuperficial, mantendo assim, a perenidade de rios e córregos associados na estação seca do ano. 
Quanto à tipologia de campos de murundus Schneider (1996) apresenta três modelos que ocorrem na alta bacia do rio Uberabinha: depressões fechadas de topo; cabeceira de drenagem; e vertentes de vales. Dentre estes tipos, ocorrem mudanças no formato das depressões e localização, indicando possíveis estádios de evolução. As depressões fechadas de topo são circulares ou elípticas não estando interligadas de forma perene a nenhum canal fluvial. As depressões associadas a cabeceiras de drenagem possuem forma alongada similar a uma gota d'água, tendo conexão com o curso fluvial superficialmente, por uma faixa linear mais estreita, possuindo murundus enfileirados no seu entorno, tal como ocorre no campo de murundus analisado. Por fim, os campos de murundus que ocorrem em vertentes de vales margeiam em formato linear as planícies de inundação de cursos fluviais, Schneider (1996) os interpreta como áreas de ocupação mais antigas por murundus, que estão sendo destruídas pelo entalhamento do vale fluvial.

Existem algumas hipóteses sobre a origem e evolução dos murundus que podem ser divididas em duas linhas de pensamento biótica e abiótica. Destaca-se na literatura brasileira o trabalho de Oliveira Filho (1988), que apoia a teoria biótica utilizando como principal referência o trabalho realizado por Methews (1977). Segundo o autor, murundus estão relacionados à atividade de várias gerações de espécies de térmitas na construção do montículo, sendo as primeiras colónias de espécies adaptadas a umidade constante no ambiente dos campos de murundus. Tais colônias teriam sido destruídas por animais como tamanduás e tatus e reconstruídas por outras espécies de térmitas que não necessariamente eram adaptadas a umidade, por estarem acima do nível do lençol freático. A sucessão de construção da colónias e destruição teria dado o formato convexo atual e criado condições para instalação da vegetação em seu topo.

Os trabalhos que consideram a hipótese de formação abiótica para os murundus têm grande apoio na geomorfologia e dinâmica superficial das águas, sendo que nesta perspectiva, a erosão diferencial consiste no principal fator para a origem dos montículos. Destacam-se os trabalhos realizados por Penteado-Orellana (1980), Araújo Neto (1981), Batista et al. (2013) e demais pesquisadores de Brasília que seguem a mesma linha de raciocínio.

De acordo com Araújo Neto (1981), os murundus seriam formados por processos de erosão superficial, por constituírem unidades mais resistentes a erosão do solo, sendo os núcleos resistentes de origem laterítica recoberto por gramíneas, o que impede o transporte superficial. Batista et al. (2013) aprofundando as análises feitas por Araújo Neto (1981), explicam como ocorre o processo geoquímico de precipitação do ferro em Gleissolos para formação dos lateritos. De acordo com Batista et al. (2013) o sistema funciona da seguinte forma:

O Fe3+ é reduzido por condições de hidromorfismo gera Fe2+, que é solúvel e, portanto, pode ser mobilizado por fluxos oblíquos de água. Esse ferro deposita-se nas porções inferiores, gerando plintita, que, quando exposta a condições de oxirredução, endurece, formando os lateritos. As amostras dessa porção apresentam um predomínio de goethita $(\mathrm{FeO}(\mathrm{OH}))$ e hematita (Fe2O3). Na porção superior topograficamente, devido à presença de água e de condições de acidez do meio, a caulinita é quebrada, transformando-se em gibbsita (BATISTA et al. 2013, p. 57).

Os lateritos formados são em muitas das vezes vesiculares, facilitando o acumulo de sedimentos, que posteriormente são colonizados pela vegetação, considerados os pontos de maior resistência aos processos erosivos, sendo a área limítrofe dos lateritos vesiculares, mais susceptível à erosão conforme a Figura 4. 


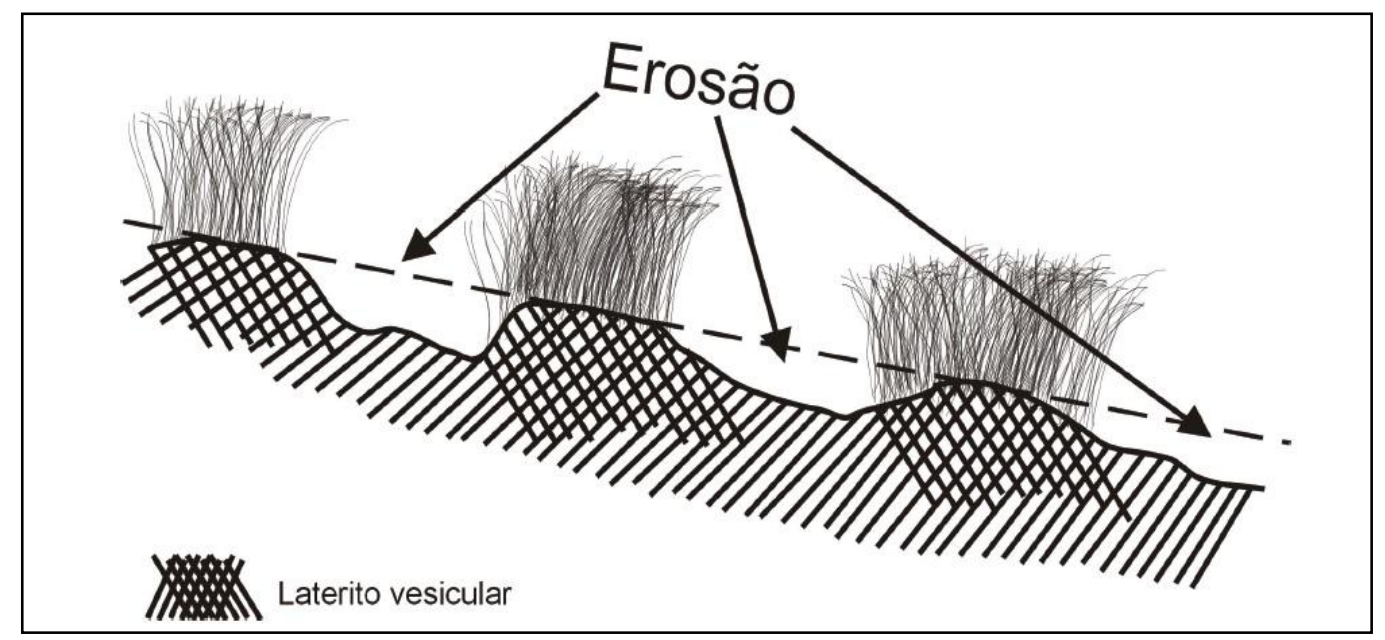

Figura 4 - Processo de erosão diferencial como hipótese para formação dos murundus

Fonte: Adaptado de Batista et al., (2013).

A partir de interpretações geomorfológicas Penteado-Orellana (1980) propõe outro cenário de evolução para a formação dos murundus, baseada nas oscilações climáticas holocênicas, tendo como protagonista a morfogênese fluvial e depósitos de pedimentos em fundo de vale, associados a episódios climáticos quente/úmidos e quente/secos. A autora propôs um modelo de evolução dos vales fluviais que explicam a existência dos murundus associados a rede de drenagem. Como base se apoiou na curva de Fairbridge (1962) que assinala as posições relativas do nível do mar à oscilações climáticas para América do sul, e nos trabalhos realizados na depressão Periférica Paulista (PENTEADO, 1968).

De acordo com Penteado-Orellana (1980) houve quatro fases marcantes no período Holoceno que caracterizaram a formação dos murundus em fundo de vale, são elas: Fase 1- clima seco acentuado com pedimentação; alargamento dos vales com pavimentação dentrítica. Fase 2 - oscilação úmida; alteritos e solos; incisão dos vales. Fase 3 - Seco; pedimentação e embutimento e alargamento de vales; Coluviação sobre várzeas; expansão das rampas coluviais; Fase 4 - incisão de talvegues; retomada erosiva; seccionamento de rampas de colúvio e formação dos montículos.

Quanto a evolução das depressões onde são encontrados os murundus, também existem duas propostas distintas. Schneider (1996) aponta os processos geoquímicos de abatimento do relevo como responsáveis pela formação das depressões, teoria muito similar a formação das veredas na fase inicial.

Mamede et al., (1983) propõe outra explicação para a ocorrência destas depressões, considerando-as como "bajadas" residuais de antigas drenagens endorreicas, formadas durante um clima mais seco que o atual.

As diversas hipóteses e teorias apresentadas sucintamente aqui, não são totalmente excludentes, sendo que vários autores agregam as propostas tentando compreender os processos em diferentes regiões do país.

\section{RESULTADOS E DISCUSSÕES}

A partir da realização dos trabalhos de campo foi possível identificar algumas das características descritas na revisão bibliográfica, subsidiando as conclusões sobre a possível gênese dos murundus na chapada Uberlândia-Uberaba.

A ilustração do perfil transversal realizado no campo de murundus da nascente do Rio da Rocinha possibilitou visualização precisa da forma dos murundus, e da depressão em topo plano que consiste em sua área de ocorrência conforme a Figura 5. Pode-se observar que o campo de murundus possui um sentido que fluxo de drenagem superficial para o centro da depressão, onde ocorre uma lagoa temporária, que abastece o Rio da Rocinha consistindo em sua principal nascente. 
Quanto ao regime hidrológico do campo de murundus, foi confirmada sua sazonalidade entre períodos chuvosos e de seca durante o ano. As Figura 6A e 6B representam a lagoa temporária no final do período seco mês de agosto (inverno) e no auge do período chuvoso mês de fevereiro (verão). A mudança sazonal do regime hidrológico dos Cerrados é um dos fatores que possibilita a formação da depressão por processos geoquímicos de abatimento do relevo, condicionada por fraturas no substrato, que também favorece o processo de erosão diferencial.

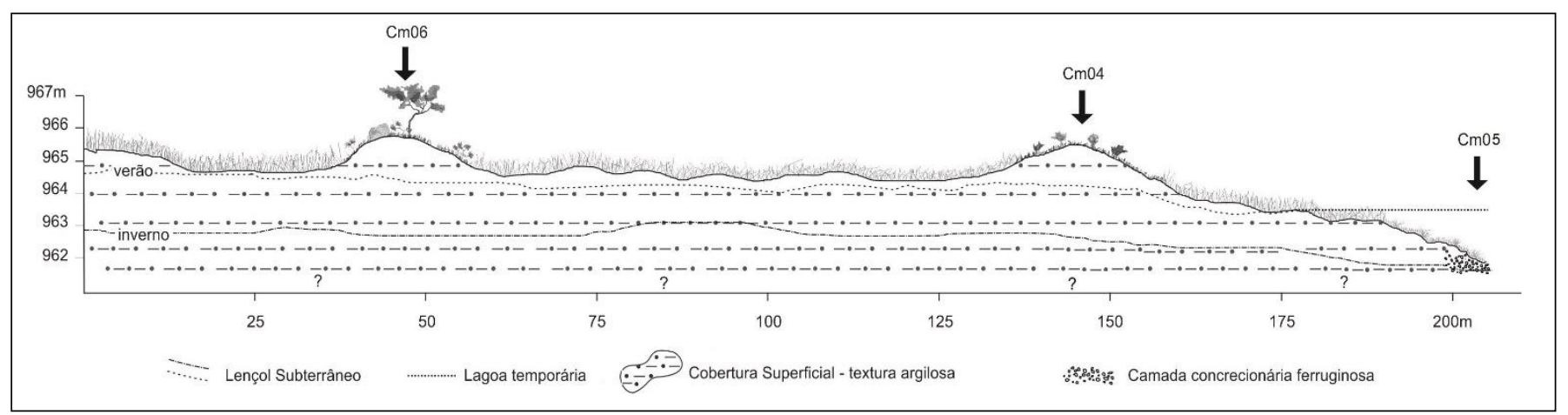

Figura 5 - Perfil transversal do campo de murundus na nascente do Rio da Rocinha

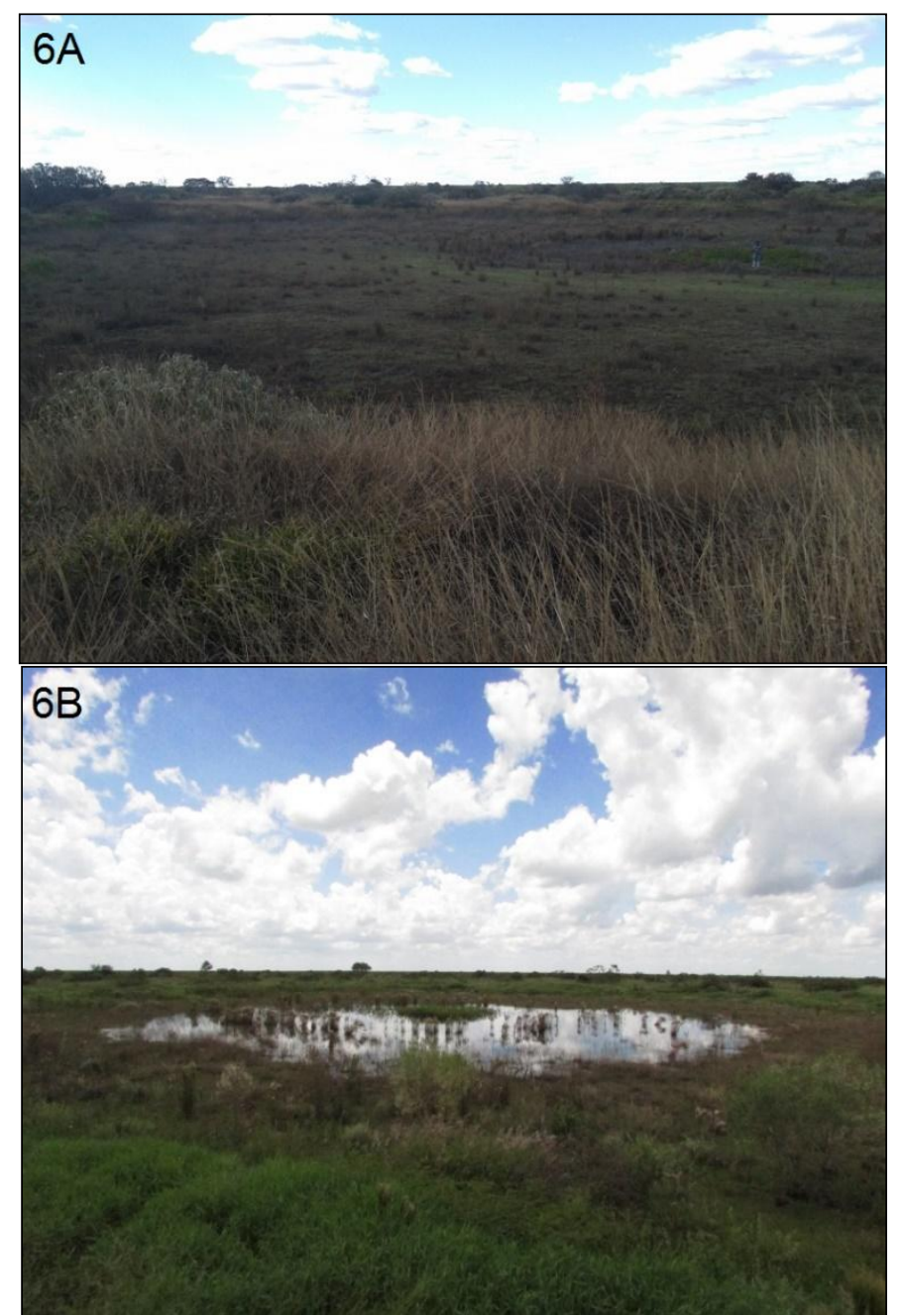

Figuras 6A e 6B - Lagoa temporária período seco (mês de agosto) e período chuvoso com água (mês de fevereiro) 
Durante as tradagens e abertura de trincheiras para coleta de amostras foi possível observar que o material no interior dos murundus é homogêneo, não variando de cor ou textura nas profundidades analisadas. No ponto CM05 foi encontrado na profundidade de 60-80 cm camada concrecionária ferruginosa densa, não sendo possível aprofundar a coleta de amostras. Segundo Penteado-Orellana (1980) as camadas concrecionárias correspondem a base dos campos de murundus, que em nossa interpretação possui a função de impermeabilização, retardando o processo de percolação da água no solo, fazendo com que o nível freático se mantenha muito superficial, cumprindo a mesma função da camada argilosa descrita por Castro Junior et al. (2004).

A análise granulométrica possibilitou conhecer a textura da cobertura superficial em campos de murundus. Os resultados demonstraram um terxtura muito argilosa em todos os pontos coletadas nas duas profundidades analizadas, confirmando a homogeinedade do material indentificada previamente em campo conforme as Tabelas $\mathbf{2}, \mathbf{3}$, e 4 .

De forma geral a quantidade de areias em 0-20 cm é maior do que nas outras profundidades. Creditamos esta caracteristica ao escoamento superficial pluvial que transporta este marterial por arraste de áreas adjacentes.

As caracteristicas texturais da cobertura superficial analisada correspondem aos atributos da unidade litoestratigráfica Coberturas Cenozoicas descrita por Barcelos (1984), que corresponde ao material de origem dos campos de murundus na chapada, sendo indicativo primordial para compreender a genese destes ambientes.

Tabela 2 - Análise Granulométrica - Ponto CM04

\begin{tabular}{|c|c|c|c|c|c|c|c|c|}
\hline & \multicolumn{6}{|c|}{ AREIA } & \multirow[b]{2}{*}{ ARGILA } & \multirow[b]{2}{*}{ SILTE } \\
\hline \multirow[t]{2}{*}{ Profundidade } & $\begin{array}{l}\text { Muito } \\
\text { Grossa }\end{array}$ & Grossa & Média & Fina & $\begin{array}{l}\text { Muito } \\
\text { Fina }\end{array}$ & $\begin{array}{l}\text { AREIA } \\
\text { TOTAL }\end{array}$ & & \\
\hline & \multicolumn{8}{|c|}{ g/kg } \\
\hline $0-20 \mathrm{~cm}$ & 8 & 11 & 21 & 18 & 18 & 76 & 741 & 183 \\
\hline $60-80 \mathrm{~cm}$ & 1 & 6 & 19 & 21 & 16 & 63 & 739 & 198 \\
\hline
\end{tabular}

Tabela 3 - Análise Granulométrica - Ponto CM05

\begin{tabular}{|c|c|c|c|c|c|c|c|c|}
\hline \multirow{3}{*}{ Profundidade } & \multicolumn{6}{|c|}{ AREIA } & \multirow[b]{2}{*}{ ARGILA } & \multirow[b]{2}{*}{ SILTE } \\
\hline & $\begin{array}{l}\text { Muito } \\
\text { Grossa }\end{array}$ & Grossa & Média & Fina & $\begin{array}{l}\text { Muito } \\
\text { Fina }\end{array}$ & $\begin{array}{l}\text { AREIA } \\
\text { TOTAL }\end{array}$ & & \\
\hline & \multicolumn{8}{|c|}{ g/kg } \\
\hline $0-20 \mathrm{~cm}$ & 26 & 62 & 113 & 59 & 21 & 281 & 641 & 78 \\
\hline $60-80 \mathrm{~cm}$ & 14 & 21 & 40 & 22 & 14 & 111 & 725 & 164 \\
\hline
\end{tabular}

Tabela 4 - Análise Granulométrica - Ponto CM06

\begin{tabular}{|c|c|c|c|c|c|c|c|c|}
\hline \multirow{3}{*}{ Profundidade } & \multicolumn{6}{|c|}{ AREIA } & \multirow[b]{2}{*}{ ARGILA } & \multirow[b]{2}{*}{ SILTE } \\
\hline & $\begin{array}{l}\text { Muito } \\
\text { Grossa }\end{array}$ & Grossa & Média & Fina & $\begin{array}{l}\text { Muito } \\
\text { Fina }\end{array}$ & $\begin{array}{l}\text { AREIA } \\
\text { TOTAL }\end{array}$ & & \\
\hline & \multicolumn{8}{|c|}{$\mathrm{g} / \mathrm{kg}$} \\
\hline $0-20 \mathrm{~cm}$ & 14 & 13 & 20 & 18 & 15 & 80 & 739 & 181 \\
\hline $40-60 \mathrm{~cm}$ & 3 & 6 & 14 & 15 & 13 & 51 & 754 & 195 \\
\hline
\end{tabular}

Na realização dos trabalhos de campo foi possível observar que nem todos os murundus possuíam termiteiros e pequenas arvores em seu topo, sendo características de apenas alguns dos microrrelevos analisados. É comum haver confusão conceitual na literatura entre murundus e termiteiros/cupinzeiros, porém sua estrutura, material, forma, tamanho e localização espacial são totalmente divergentes, havendo necessidade de trabalhos de campo e coletas de amostras para distinguir os murundus dos termiteiros. 
A partir das coletas por meio de tradagem e abertura de trincheiras pode-se ter uma ideia da composição interna dos murundus, possibilitando ilustrar um corte transversal demonstrando sua característica externa e interna Figura 7A e 7B. As térmitas são importantes agentes de remobilização de sedimento e solos, porém não atuam no interior do murundu, somente ocupam o topo da sua superfície fugindo da umidade na base, construindo seus dutos no horizonte " $\mathrm{A}$ " e formando seu termiteiro na parte externa ao murundu.
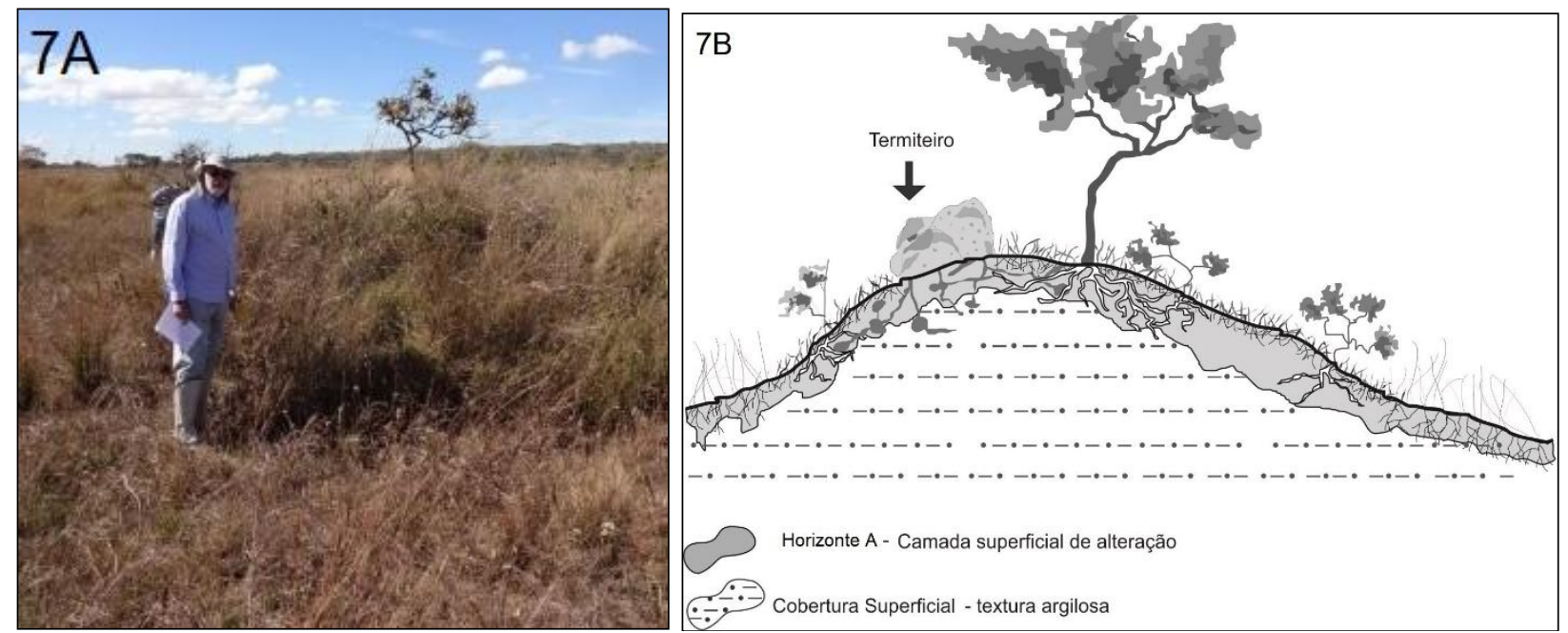

Figuras 7A e 7B - Murundus característica externa e corte transversal ilustrando composição interna

Estas observações em campo nos levam a considerar como hipótese mais coerente para a área de estudo a teoria de formação abiótica, onde os insetos não participam da formação dos murundus, somente ocupam seu topo para fugir de predadores e da umidade em níveis mais baixos dos campos de murundus.

\section{CONCLUSÕES}

Os resultados encontrados por meio da metodologia e técnicas aplicadas demonstraram compatibilidade com parte da bilbiografia apresentada, possibilitanto um posicionamento neste tema tão complexo que é a caracterização física e genese dos murunudus.

A dinâmica hídrica associada ao clima sazonal da região se caracteriza como importantes agentes que possibilitaram a ocorrência de processos geoquímicos de abatimento do relevo, dando origem as depressões que consistem em áreas de ocorrência dos murundus, base para os depósitos da Cobertura Cenozoica.

A análise granulométrica demostrou que os munrundus possuem cobertura superficial muito argilosa nas profundidades investigadas, sendo originados do material da Cobertuda Cenozoica que possui caracteristica similar, portanto, as microformas de murundus pertencem a um período muito recente, provavlemente holocênico, correspondente ao retrabalhamento da litoestratigrafia Cobertura Cenozoica.

Concluindo as evidencias de processos abióticos identificados, acredita-se que a erosão diferencial ocorre num estádio mais avançado, entalhando os depósitos de coberturas superficiais menos resistentes, dando origem as microformas de murundus. Desta forma podemos concluir que a formação dos murundus é anterior a ocupação das térmitas que ocorreria em fase posterior, quando a forma já estaria estabelecida por processos abióticos, pois não foram encontradas evidencias de dutos ou remobilização de material interno aos murundus. 


\section{REFERÊNCIAS}

ARAÚJO NETO, M. D. Solos, água e relevo dos campos de murundus na Fazenda Água Limpa, Distrito Federal. Dissertação (Mestrado em Biologia) - Departamento de Biologia Vegetal, Universidade de Brasília, Brasília, 1981.

BARCELOS, J. H. Reconstrução Paleogeográfica da Sedimentação do Grupo Bauru Baseada na sua Redefinição Estratigráfica Parcial em Território Paulista e no Estudo Preliminar Fora do Estado de São Paulo. Rio Claro, 1984. 190p. Tese (Livre Docência) - Instituto de Geociências e Ciências Exatas, Universidade Estadual Paulista, Rio Claro, 1984.

BATISTA, G, M, M; CORRÊA, R, S; SANTOS, P, F. Campos de Murundus da fazenda água limpa da UNB: hipótese de origem. Revista do Ceam. V.2, N.1, p. 47-60. 2013.

CAMARGO, O.A.; MONIZ, A.C.; JORGE, J.A. \& VALADARES, J.M. Métodos de análise química, mineralógica e física de solos do Instituto Agronômico de Campinas. Campinas: Instituto Agronômico de Campinas, 1986, 94p. (IAC - Boletim Técnico, 106).

CASTRO JUNIOR, P. R. Dinâmica da água em campos de murundus no planalto dos Parecis. 2002. 195 p. Tese (Doutorado em Geografia) FFLCH-USP. São Paulo. 2002.

CASTRO JUNIOR, P,R; GIRARD, P; CUNHA, C, N, da. Dinâmica hídrica em campos de murundus. In: XIII Congresso Brasileiro de Águas Subterrâneas. Anais. São Paulo-SP. P. 1-18, 2004.

EMPRESA BRASILEIRA DE PESQUISA AGROPECUÁRIA - EMBRAPA. Manual de métodos de análise de solo. 2.ed. Rio de Janeiro, Centro Nacional de Pesquisa de Solos, 1997. 212p.

FAIRBRIDGE, R.W. World sea-level and climatic changes. Quaternaria, (6), p.11l-134. 1962.

MAMEDE, L; ROSS, J, L, S; SANTOS, L, M; NASCIMENTO, M, A, L, S. RADAMBRASIL Folha SE-22. Goiânia: Geomorfologia. Rio de Janeiro: Ministério das Minas e Energia / Secretaria Geral, v. 31. 1983. P 338410.

MATHEWS, A, G, A. Studies on térmites from the Mato Grosso State, Brazil. Rio de Janeiro, Academia Brasileira de Ciências, 267p, 1977.

OLIVEIRA-FILHO, A. T. de. A vegetação de um campo de monchões microrrelevos associados a cupins na região de Cuiabá (MT). 1988. 168 p. Tese de doutoramento IB-UNICAMP, Campinas, SP, 1998.

PENTEADO, M.M. Geomorfologia do Setor Centro-Ocidental da Depressão Periférica Paulista. 1968. 195p. (Tese de Doutoramento). UNESP, Rio Claro, 1968.

PENTEADO-ORELLANA. M. M. Microrrelevos associados a térmitas no Cerrado. Notícias Geomorfológicas, Campinas. V. 20, N. 39/40, p. 61-72. 1980.

ROSA. LIMA, S, C; ASSUNÇÃO, W, L. Abordagem preliminar das condições climáticas de Uberlândia. Sociedade \& Natureza. Uberlândia, V. 5 e 6, n. 3, p.91-108. Dez. 1991.

SCHNEIDER, M.O. Bacia do Rio Uberabinha: Uso agrícola do solo e meio ambiente. 1996. 157p. Tese (Doutorado em Geografia Física) - Faculdade de Filosofia, Letras e Ciências Humanas, Universidade de São Paulo, São Paulo, 1996.

SCHNEIDER, M.O; SILVA, D, B. da. Estrutura pedológica e dinâmica hídrica do "covoal” córrego da fortaleza. Sociedade \& Natureza, Uberlândia, v.3, n. (5 e 6), p.75-89, Dezembro, 1991.

UNIVERSIDADE FEDERAL DE VIÇOSA; FUNDAÇÃO CENTRO TECNOLÓGICO DE MINAS GERAIS; UNIVERSIDADE FEDERAL DE LAVRAS; FUNDAÇÃO ESTADUAL DO MEIO AMBIENTE. Mapa de solos do Estado de Minas Gerais. Belo Horizonte: Fundação Estadual do Meio Ambiente, 2010. 